\title{
AGROINDÚSTRIAS RURAIS FAMILIARES E NÃO FAMILIARES: UMA ANÁLISE COMPARATIVA
}

\author{
FAMILY AND NON-FAMILYRURAL AGRO-INDUSTRIES: A \\ COMPARATIVE ANALYSIS
}

\author{
Lillian Bastian \\ Universidade Federal do Rio Grande do Sul - RS - Brasil \\ Paulo Dabdab Waquil \\ Universidade Federal do Rio Grande do Sul - RS - Brasil \\ Mônica Concha Amin \\ Fundação Universidade Federal de Ciências da Saúde de Porto Alegre - RS - Brasil \\ Marcio Gazolla \\ Universidade Federal de Santa Maria - RS - Brasil
}

\begin{abstract}
Resumo: Recentemente, são observadas inúmeras alterações no espaço rural, tais como a introdução de novas tecnologias, integração agroindustrial e a valorização enquanto lugar de moradia, lazer, produtos saborosos e saudáveis. Na esteira dessas transformações, alguns agricultores começam a perceber que existem novas possibilidades de geração de renda. Uma dessas novas oportunidades surge através do incremento da produção agroindustrial, uma atividade que é típica da agricultura familiar. Interessando-se por esta temática é que neste artigo objetiva-se verificar se há distinções e quais são estas distinções entre as agroindústrias rurais da agricultura familiar e da agricultura não familiar, em nível de Brasil. Inicialmente salienta-se que as agroindústrias rurais são heterogêneas entre si ficando difícil fazer inferências sobre dados agregados. Entretanto, a separação dos dados entre agroindústrias da agricultura familiar (AF) e da agricultura não familiar (ANF) já possibilita um recorte. Partindo desse pressuposto, foram selecionadas algumas variáveis do Censo Agropecuário de 2006 para inferir sobre oito produtos da agroindústria rural. Deste modo, através destes dados e destas variáveis identificou-se que a agroindústria rural é mais numerosa nos estabelecimentos familiares, um vez que a produção total provém principalmente dela, com exceção de dois produtos em que a produção entre a AF e ANF é praticamente equivalente. Para a escala de produção verificou-se que, para seis produtos analisados, ela é superior na ANF e em dois na AF. A ANF também se destaca com maior proporção de matérias-primas adquiridas, e maior proporção de comercialização. Os canais de comercialização são praticamente idênticos, com alguma exceção, contanto que a AF venda mais para o consumidor final e a ANF aos intermediários. As conclusões apontam que as distinções entre esses dois tipos de agroindústrias estão fortemente ligadas à lógica que as gerencia, pois na maioria das propriedades da ANF há especialização e na AF diversidade, o que consequentemente gera maneiras distintas de atuarem em suas agroindústrias.
\end{abstract}

Palavras-chave: Agroindústria rural. Agricultura familiar (AF). Agricultura não familiar (ANF).

Abstract: Recently, innumerable alterations have been observed in rural areas, such as the introduction of new technologies, agro-industrial integration and valuing of these areas as living and leisure places, having delicious and healthy products. In the wake of these transformations, some farmers have begun to realize that there are new possibilities of generating income. One of these opportunities has arisen through the development of agro-industrial production as a typical activity of family agriculture. By an interest in this subject, this article aims to verify if there are distinctions, and what are the distinctions between rural agro-industries of family and non-family agriculture, to the level of Brazil. Initially, rural agro-industries that are heterogeneous among them have been highlighted, being difficult to make inferences on aggregated data. However, the separation of data 
between agro-industries of family agriculture (FA) and non-family agriculture (NFA) has already made possible a cutout. Based on this assumption, some variables were selected from the Agricultural Census of 2006 to infer on eight products from the rural agro-industry. This way, through these data and variables, it was possible to identify that the rural agro-industry is more numerous in family establishments, as well as its total production coming mainly from it, with the exception of two products which production, between FA and NFA, is basically equivalent. Through the variable scale of production for the six analyzed products, it was possible to verify that they were above in NFA, and two in FA. The NFA is also highlighted with acquired raw material and commercialization in a greater proportion. In addition, commercialization channels are practically identical, with some exception, as long as the FA sells more to the final consumer and NFA to intermediate consumers. The conclusion have indicated that the distinctions between these two types of agro-industries are strongly connected to the logistics that manage them, once, in the majority of the proprieties of NFA, there is specialization and diversity in FA, what generates, consequently, distinct manners of operating in their agroindustries.

Key words: rural agro-industry, family agro-industry (FA), non-family agriculture (NFA).

\section{Introdução}

Atualmente, algumas transformações processam-se no espaço rural. Algumas delas surgem como consequência do modelo tecnológico de produção agrícola que mudou a forma como a agricultura acontecia, introduzindo máquinas mais potentes, adubos químicos, agrotóxicos, sementes híbridas ou transgênicas e novas técnicas. Apesar de aumentar a produção, essa mudança causou problemas ao ambiente, exclusão social da atividade agrícola e diminuição das rendas dos agricultores. Outra alteração neste espaço surge com a introdução de cadeias longas de produção agroindustrial onde através da integração, os agricultores se comprometem a produzir e as agroindústrias se responsabilizam pelo restante das etapas de transformação das matérias-primas para 0 consumo final. Estas alterações ocorrem no rural de uma maneira que vem do exterior deste espaço para o interior dele e muitas vezes não são compatíveis às inúmeras e diferenciadas realidades (MIOR, 2007).

Contudo o espaço rural é dinâmico, e na contramão deste processo de homogeneização está ocorrendo, na escala regional, a valorização do rural por suas diversidades. Assim o rural também passa a figurar como um local de descanso, de alimentos saborosos e diferenciados, de lazer e até mesmo de moradia (FROEHLICH, 2002). A partir dessa perspectiva, se desfaz a percepção do rural atrasado, surgindo nele qualidades antes imperceptíveis.

Esse contexto heterogêneo que circunda o rural, ao mesmo tempo em que parece ser opressor das diversidades, pode estar criando novas possibilidades na medida em que os agricultores podem usar o ganho de estima do rural para inovar e fugir do modelo tecnológico e da cadeia longa de produção agroindustrial. Muitas das inovações compõem novas estratégias de reproduzir-se no rural, como é o caso do incremento da produção da agroindústria.

A produção agroindustrial acontece ancorada na culinária regional e concentra a sua produção em distintas regiões devido às características edafoclimáticas e culturais (MIOR, 2008; BASTIAN et al, 2011). Desse modo, a farinha de mandioca, proveniente da matéria prima mandioca, é produzida principalmente nas regiões Nordeste e Norte porque aí existem condições climáticas compatíveis com a produção dessa raiz, estando o hábito de produzir e de consumir a farinha enraizado nos costumes de famílias rurais. 
As técnicas de processamento agroindustrial ocorrem no espaço rural brasileiro desde a colonização europeia quando os imigrantes adotaram essas práticas para conservar alimentos (PREZZOTO, 2002). Entretanto, no período recente a agroindustrialização vem sendo percebida como uma maneira de complementar a renda (MIOR, 2008). Isso surge porque pode haver baixa oferta e muita demanda por um determinado produto da agroindústria rural. Essa situação pode desencadear 0 surgimento de unidades agroindustriais maiores das que existem nas cozinhas dos estabelecimentos rurais, destinando-se a atender o mercado local e regional.

É com base nesse contexto que no Oeste de Santa Catarina, desde a década de 1990, surgiram muitas agroindústrias rurais familiares. Essas agroindústrias são autônomas, pois foram os agricultores que as fundaram e que as gerenciam. Nelas são processadas diferenciadas matérias-primas como leite, carne suína, cana de açúcar e frutas (MIOR, 2008).

A quantidade de inovações nesta temática da agroindústria rural, não somente no Oeste Catarinense, mas também em outras regiões do Brasil, desperta o interesse de acadêmicos e de instituições que tentam compreender com mais clareza qual a dimensão deste processo, como os alimentos agroindustrializados são comercializados, a agregação de valor dentre outros fatores que se ligam a esta atividade (MIOR, 2008).

Uma das instituições que se dedica a coletar dados sobre as agroindústrias rurais é o Instituto Brasileiro de Geografia e Estatística - IBGE. Através do Censo Agropecuário são coletadas informações tais como: alimentos que são produzidos, em que quantidade, qual o preço pago por eles, qual a origem da matéria-prima, em que proporção a produção é comercializada. Para coletar essas informações o IBGE adota um conceito, uma denominação normativa para agroindústrias rurais que as compreende como atividades de beneficiamento e transformação de matérias-primas animais ou vegetais de origem do próprio estabelecimento ou adquiridas de outros produtores, que usam para o beneficiamento ou transformação instalações próprias, comunitárias ou de terceiros desde que a destinação do produto final seja dada pelo produtor (IBGE, 2006).

Esse conceito abarca todas as experiências em agroindustrialização que ocorrem no espaço rural, mas, na medida em que esses dados são divulgados de maneira agregada, não possibilitam uma análise de cada uma das diferentes experiências da agroindústria, pois, segundo Guimarães e Silveira (2010), é difícil incluir em um mesmo conceito todas as agroindústrias rurais que existem no espaço rural, uma vez que elas podem ter diferentes escalas de produção; produzir um produto padronizado ou artesanal; utilizar conhecimentos herdados de antepassados ou técnicas mais industrializadas; ser formais ou informais; vender em diferentes proporções. Desse modo, são diversas as tipologias de agroindústrias e quando se utiliza dados agregados, como os do Censo Agropecuário, as inferências são feitas de maneira geral para todos esses tipos.

Entretanto, apesar dessa mistura, o IBGE formulou algumas tabelas em que estão separados os dados dos estabelecimentos da agricultura familiar (AF) dos da agricultura não familiar (ANF), proporcionando que, em um aspecto das diversidades agroindustriais existentes no Brasil, os dados se encontrem desagregados. A partir de tudo isso que foi exposto até aqui, este artigo se propõe a verificar se há distinção e quais são estas distinções entre a agroindústria rural familiar e não familiar no Brasil. 
Cabe destacar que este artigo é um dos produtos do acordo de cooperação entre o Instituto de Pesquisa Econômica Aplicada (IPEA) e o Programa de Pós-Graduação em Desenvolvimento Rural da Universidade Federal do Rio Grande do Sul (PGDR-UFRGS), denominado "Projeto de pesquisa de equipe para análise dos dados do novo Censo Agropecuário 2006". Especificamente este trabalho é integrante de um dos subprojetos que visou compreender, através da análise dos dados do Censo Agropecuário 2006, "O perfil da agroindústria rural no Brasil". Para atender a esse objetivo, inicialmente dois artigos foram formulados, de Niederle et al. (2011) e de Bastian et al. (2011). Esses artigos descreveram, em nível de macrorregiões brasileiras, os canais de comercialização da produção e o perfil produtivo das agroindústrias rurais. Posteriormente outros dois artigos foram formulados. Um deles caracterizou a espacialização da produção agroindustrial rural brasileira. E o outro fez uma comparação setorial em nível de macrorregiões brasileiras entre os alimentos da agroindústria e entre agricultura familiar e não familiar para analisar a agregação de valor. Destaca-se que todos esses artigos analisaram dentre oito e nove dos alimentos selecionados para coleta de dados da agroindústria rural no Censo Agropecuário de 2006 (na metodologia encontra-se citado quais são esses alimentos e como foram selecionados).

Em termos de estrutura, este artigo é composto por esta introdução e mais quatro seções. Dentre elas está um referencial teórico que aponta, principalmente, a diversidade das agroindústrias rurais. Na sequência, há a descrição dos procedimentos metodológicos bem como o conceito de AF e ANF adotado pelo IBGE e seleção das variáveis. Subsequentemente estão os resultados que apresentam as principais diferenças entre AF e ANF e por último constam algumas considerações finais.

\section{A DIVERSIDADE DAS AGROINDÚSTRIAS: DO CONSUMO PRÓPRIO À PRODUÇÃO PARA COMERCIALIZAÇÃO}

Ao se falar de agroindústrias pode-se incluir desde aquelas que estão em propriedades de agricultores familiares ou não familiares, até as grandes agroindústrias que se encontram localizadas no espaço urbano ou rural e muitas vezes não têm ligação com a população rural, além de obterem dos agricultores os produtos in natura para industrializá-los. Observando apenas as que têm vínculos mais fortes com o rural, atualmente nota-se que as agroindústrias familiares e não familiares, mas principalmente as localizadas em unidades familiares, têm se expandido e obtido reconhecimento.

Apesar de terem aumentado a escala de suas produções no período mais recente, Prezzoto (2002) cita que o processamento e a transformação de matérias-primas, técnicas usadas para agroindustrializar matérias-primas, não se constituem em uma novidade para os agricultores familiares descendentes de imigrantes europeus, pois esses aprenderam essas técnicas de preparo de alimentos com seus antepassados. Segundo Guimarães e Silveira (2010), as técnicas de processamento de alimentos de origem vegetal e animal constituíram se em uma maneira encontrada pelos imigrantes europeus para conservar os alimentos em um período que ainda não havia entre os agricultores a atual tecnologia de refrigeração que prolonga a vida útil dos alimentos, principalmente as carnes in natura.

Assim, técnicas utilizadas no preparo de alimentos agroindustrializados se constituem em parte da lógica de funcionamento da agricultura familiar. Inicialmente, essas técnicas eram mais direcionadas à subsistência da família, produção para o autoconsumo e, 
posteriormente, foram assumindo em diferentes realidades rurais e de diferentes formas, um caráter de geração de renda (MIOR, 2008). Segundo Mior (2007), os agricultores, que perceberam que os produtos agroindustrializados poderiam ser uma possibilidade de acrescentar recursos financeiros aos obtidos através das atividades agrícolas, aumentaram a quantidade de produtos processados e transformados com intuito de destiná-los ao mercado.

Essas iniciativas agroindustriais estão ligadas às transformações recentes do espaço rural, principalmente aquelas ligadas à modernização agrícola e à integração agroindustrial que causaram diminuição dos ganhos e dependência de uma grande cadeia de produção de alimentos $^{1}$. No oeste catarinense ${ }^{2}$, por exemplo, Mior (2008) identificou que a introdução de agroindústrias convencionais da cadeia dos suínos, com interesse de integrar-se com agricultores familiares, levou à exclusão de muitos agricultores da atividade de produção agrícola. Muitos que se integraram não conseguiram acompanhar as exigências destas agroindústrias e outros, que optaram por continuar com a produção autônoma, não tiveram condições de competir com a grande agroindústria convencional. Nesse caso, apesar desta situação de exclusão, os agricultores alargaram seus horizontes e perceberam outras possibilidades de geração de renda, direcionando-se para a agregação de valor às matériasprimas que já eram produzidas na propriedade. Dessa forma, é que começaram a surgir as agroindústrias rurais.

Outro fator que tem contribuído para o fortalecimento das agroindústrias no rural é a valorização do produto artesanal/colonial. Muitos consumidores obtêm produtos provenientes da localidade por saberem qual a procedência, conhecerem as pessoas que os elaboraram e apreciarem o seu sabor que é originário de um saber fazer herdado de gerações anteriores que, conciliado com as características de cada região, incluem nos produtos um gosto específico. Guimarães e Silveira (2010), salientam que este sabor específico provém da arte que cada pessoa emprega no momento de processar e transformar o alimento, melhorando a receita herdada e o seu modo de fazer, incluindo em cada produto um detalhe em diferencial, desse modo, atribuindo-lhe características específicas. Muitos consumidores que conhecem a procedência dos produtos não se importam se este é produzido conforme as exigências legais de sanidade, pois eles conhecem os produtores e confiam que os alimentos manufaturados por eles são de qualidade. Em algumas das propriedades, que começam a destinar agroindustrializados para este nicho, ocorre a construção de agroindústrias com o intuito de legalizá-las, mas muitas delas continuam operando na informalidade (WILKINSON e MIOR, 1999).

Além da percepção dos próprios agricultores sobre a possibilidade de geração de renda, através da elaboração e venda de produtos agroindustrializados, no ambiente institucional verifica-se a criação de alguns programas com o intuito de implantar as agroindústrias no espaço rural. Em nível nacional tem destaque o Programa de Agroindustrialização da Agricultura Familiar com origem em 2003. Em níveis estaduais,

\footnotetext{
${ }_{1}$ Além de serem originárias desta transformação do rural, as agroindústrias surgem em um período que começa a ficar evidente que o rural não se constitui somente na produção agrícola, mas é um espaço diverso e de pluriatividade com qualidades ligadas à produção de alimentos mais saudáveis, de lazer e turismo, de natureza, dentre outras características.

${ }_{2}$ Para construção deste referencial teórico utilizou-se bibliografias fundamentadas em pesquisas que analisaram as agroindústrias que se encontram na região Sul do Brasil. Nas demais regiões, especialmente no Nordeste e no Sudeste, também existem agroindústrias, mas não encontramos artigos que retratassem os inúmeros aspectos que estão relacionados às suas agroindústrias.
} 
pode-se citar o Programa da Agroindústria Familiar implantado no Rio Grande do Sul de 1999 a 2002 e o Programa de Desenvolvimento da Agricultura Familiar pela Verticalização da Produção com atuação de 1998 a 2001 em Santa Catarina (WENZ JUNIOR, 2009).

As políticas públicas têm papel fundamental para o aprimoramento de experiências de processamento de alimentos no meio rural. Segundo Raupp (2009) e Guimarães e Silveira (2010), para que o auxílio proposto ocorra com sucesso, primeiramente deve-se diagnosticar o estágio em que se encontram as experiências de agroindustrialização de matérias-primas e quais são as intenções que os agricultores têm, verificando, principalmente, qual é a noção das famílias de agricultores sobre a agroindústria e quais são os objetivos que têm com esta. As políticas que são traçadas e implementadas dessa maneira, respeitando a percepção dos agricultores, têm maior possibilidade de construir inovações sem desorganizar o sistema de produção, a lógica interna de cada unidade de produção que regula as atividades conforme os recursos disponíveis.

Independente de qual é a motivação ou o estímulo para o aumento da produção proveniente da agroindústria, é necessário pensar em formas de comercialização. Segundo Mior (2008), a descoberta dos mercados ocorre fundamentada nos laços sociais que os membros da família ou das famílias que compõem a agroindústria têm. Isso porque estas agroindústrias apresentam uma rota de comercialização distinta da adotada pelas grandes agroindústrias processadoras de commodities. Elas criam o mercado para seus produtos em nível local utilizando-se dos laços sociais, de amizade e de parentesco (WENZ JUNIOR, 2009). Assim, os agricultores que estão envolvidos no processo de produção agroindustrial mobilizam atores sociais de sua localidade e de deus municípios ao redor, e usando esta aproximação social, que em muitos casos está fundamentada na confiança, criam oportunidades de comercializar. Através de táticas como estas, muitos dos alimentos produzidos nas propriedades rurais, através de processos que envolvem a transformação da matéria-prima, passam a ser vendidos no comércio local, em padarias, minimercados, bares e restaurantes, por exemplo. Outra forma de venda é em feiras ecológicas, onde os produtores saem de suas propriedades para se estabelecerem momentaneamente em um local onde comercializam os alimentos agroindustrializados diretamente com os consumidores.

Pode-se imaginar que as formas como os produtos da agroindústria são comercializados; as diferentes causas que levam ao surgimento dessas no meio rural; e os distintos espaços onde estão introduzidas, originam agroindústrias diferentes entre si. Guimarães e Silveira (2010), partindo do pressuposto de que existem variadas agroindústrias familiares no meio rural, buscam formar um marco teórico que oriente a compreensão destas diferentes situações sem pretensão de esgotar as possibilidades de modificação e/ou transição entre os distintos estratos de classificação das agroindústrias. Assim, propõem que nas experiências de processamento de alimentos no rural existam pelo menos três tipos de agroindústrias: agroindústria caseira, agroindústria familiar artesanal e agroindústria familiar de pequeno porte.

As agroindústrias caseiras se caracterizam por não terem espaço e equipamentos específicos para o processamento dos alimentos. Assim, compreende-se que estes alimentos são beneficiados na própria cozinha do estabelecimento, e são produtos elaborados para 0 consumo da família com comercialização de algum excedente. Os produtos apresentam uma boa aceitação entre os consumidores. Os agricultores que detêm este tipo de agroindústrias não têm interesse em formalizá-las, pois isso exigiria uma reorganização no sistema 
produtivo da propriedade e traria maiores custos. Nas agroindústrias familiares artesanais há uma preocupação com a sanidade dos alimentos a ponto de os agricultores reelaborarem procedimentos do modo de fazer das receitas herdadas de seus antepassados com o intuito de atribuir um caráter mais padronizado ao produto, vindo ao encontro da legislação que normatiza os aspectos sanitários. Mesmo assim, o produto elaborado nessas agroindústrias contém um aspecto artesanal: a família transforma os alimentos de maneira a atribuir-lhes um caráter específico que só é encontrado nos produtos provenientes daquela família ou de uma região onde prolifera uma mesma cultura. Por último, as agroindústrias familiares de pequeno porte são aquelas legalizadas e que diferem das demais por processarem os alimentos com base em técnicas que não estão mais vinculadas às receitas herdadas de antepassados. Os donos dessas agroindústrias aprenderam com técnicos uma maneira padrão de processamento. Deste modo, essas agroindústrias não apresentam a característica artesanal e se assemelham a agroindústrias convencionais, mas de pequeno porte (GUIMARÃES E SILVEIRA, 2010).

Debruçando-se sobre a heterogeneidade das agroindústrias, Wenz Junior (2009) traça o perfil de dois grupos de agroindústrias. No primeiro grupo encontram-se as agroindústrias que aparecem nos estabelecimentos como atividade e renda complementar, operam na informalidade ou no máximo atendem às exigências da inspeção municipal, elaboram seus produtos conforme o conhecimento tradicional, usam um local de processamento de alimentos onde são realizadas outras atividades não relacionadas; e realizam as vendas no mercado local, utilizando as relações sociais e estando próximos dos consumidores dos produtores. No segundo grupo encontram-se as agroindústrias que compõem a principal atividade e renda do estabelecimento, operam conforme a legislação em vigor ou pretendem se adequar a ela. O produto é padronizado, o local de processamento de alimentos é específico para a atividade de agroindustrialização e os produtos são comercializados, principalmente, fora da região onde se encontram as agroindústrias. Embora sejam mantidos, em menor medida, mercados regionais.

Essas definições dos autores surgem em decorrência das diversificadas maneiras como as agroindústrias se constituem no meio rural. Entretanto, apesar de esses autores estarem sensíveis à variedade de tipos de agroindústrias no rural, para algumas instituições como o Instituto Brasileiro de Geografia e Estatística (IBGE), que realiza pesquisas em todo o Brasil, tais como o Censo Agropecuário, utiliza-se uma denominação mais normativa para abarcar todas as unidades agroindustriais que possam existir. Optando por esse leque mais aberto, que inclui diferenciadas experiências de processamento e de transformação de alimentos, é possível ter uma dimensão da quantidade de alimentos que são transformados no Brasil. Assim, o IBGE compreende agroindústrias rurais como:

atividades de transformação e beneficiamento de produtos agropecuários de origem animal ou vegetal, que foram realizadas em instalações próprias, comunitárias ou de terceiros, a partir de matéria-prima produzida no próprio estabelecimento agropecuário ou adquirida de outros produtores, desde que a destinação final do produto tivesse sido dada pelo produtor (IBGE, 2006, p. 31).

Nessa conceituação estão incluídas as formas de processamento e de transformação de matérias-primas que se originam na cozinha dos estabelecimentos rurais até aquelas agroindústrias que têm seu espaço físico separado da residência da família e/ou das famílias responsáveis por ela. Desse modo, através desta definição de agroindústria os estudos 
provenientes de pesquisas realizadas pelo $I B G E$, tal como o deste artigo, não encontram uma clareza sobre que tipo específico de agroindústrias são estas que existem no rural brasileiro. Nele estão incluídas em uma mesma análise diferentes agroindústrias, familiares ou não familiares, que poderiam não ser comparáveis devido ao seu caráter relacionado à escala, instalações, infraestrutura, gestão, origem da matéria-prima, saber fazer, utilizado ou não, conhecimentos e forma de comercialização (Guimarães e Silveira, 2010).

Se nesse caso não é possível ter uma dimensão mais acurada das características das agroindústrias, através de outra base de dados fornecida pelo IBGE se obtém os dados correspondentes às agroindústrias familiares (AF) e às agroindústrias não familiares (ANF). Essa separação já é um passo importante, pois esses dois tipos de agricultura apresentam distinções relacionadas à lógica de funcionamento. De maneira geral a AF objetiva, primeiramente, atender às necessidades mais ligadas à subsistência (alcançado isso, busca-se pela obtenção de renda); já na maioria das propriedades da ANF predomina o objetivo de obter renda. Na AF a produção de gêneros animais e vegetais é diversificada; na ANF o número de atividades econômicas é reduzido, as commodities são cultivadas em grande extensão/quantidade para obter maiores ganhos de escala. A mão de obra na AF é principalmente da família, com contratação eventual de mão de obra; na ANF predomina a mão de obra contratada. A gestão da unidade de produção na AF é feita pela família; na ANF pode ser feita pelo proprietário do estabelecimento rural ou por um administrador rural.

Observando as principais diferenças entre esses dois tipos de agricultura, é de se esperar que haja diferenças também entre as agroindústrias rurais que se localizam nessas distintas propriedades. Isso é o que iremos verificar mais adiante na apresentação dos resultados que distinguem as agroindústrias familiares das não familiares e que se encontram após a explicação dos procedimentos metodológicos adotados na elaboração deste artigo.

\section{PROCEDIMENTOS METODOLÓGICOS}

Este artigo foi escrito utilizando-se de dados do Censo Agropecuário 2006. Os dados que deram origem aos resultados apontados são provenientes de tabelas reorganizadas pelo $\mathrm{IBGE}$, a partir dos dados do censo, constam variáveis da agroindústria rural conforme a sua origem, se de estabelecimentos da agricultura familiar ou de estabelecimentos da agricultura não familiar.

O IBGE distingue estas duas agriculturas, familiar (AF) e não familiar (ANF), conforme a Lei $n^{\circ} 11.326$, de 24 de julho de 2006, denominando como agricultor ou empreendedor familiar rural aqueles estabelecimentos que atendem aos seguintes itens: a área do estabelecimento ou empreendimento rural não pode exceder os quatro módulos fiscais; a mão de obra utilizada nas atividades econômicas desenvolvidas deve ser de origem predominantemente da própria família; a renda familiar é majoritariamente originada das atividades agrícolas realizadas na propriedade e o estabelecimento ou empreendimento é 
dirigido pela família (IBGE, 2009). Os estabelecimentos ${ }^{3}$ que não se enquadram em um ou mais desses itens automaticamente são classificados como não familiares.

Nesses estabelecimentos onde a agroindústria rural se faz presente, durante o Censo Agropecuário foram coletadas informações sobre 32 distintos produtos agroindustriais. Considerando ser este um número elevado, neste artigo foram selecionados somente oito deles. Para selecionar os produtos, considerou-se o nível de transformação da matériaprima, sendo selecionados os produtos onde ela foi alterada mais significativamente. Assim optou-se pelo produto embutidos, ao invés da carne tratada, por exemplo. Outro aspecto considerado no momento de selecionar os produtos foi a sua expressividade para a (macro)região e a sua importância socioeconômica (BASTIAN et al., 2011, NIEDERLI et al., 2011). A partir desses critérios de seleção, os produtos que estão em discussão neste artigo são: Aguardente de Cana, Doces e Geleias, Embutidos, Farinha de Mandioca, Fubá de Milho, Goma ou Tapioca, Queijo ou Requeijão e Rapadura ${ }^{4}$.

As variáveis de análise surgiram das tabelas fornecidas pelo IBGE em que estão separados os dados das agroindústrias da AF e da ANF. Nessas tabelas, para cada produto existem variáveis como: condição do produtor em relação às terras, grupos da atividade econômica e destino da produção consumida ou estocada. Dentre esse conjunto de variáveis, foram elencadas algumas que demonstrassem com maior efetividade se há diferenças e quais são estas diferenças entre os estabelecimentos da AF e da ANF produtores dos alimentos agroindustrializados citados acima. Considerando esse fator, as variáveis selecionadas foram: número de estabelecimentos; produção total; origem da matéria-prima, se própria ou adquirida, proporção da produção total vendida; e destinos da produção vendida. Além dessas há a variável escala produtiva (média), que se dá através da divisão da produção total pelo número de produtores. Na seção dos resultados, para cada uma destas variáveis existem gráficos ou tabelas que demonstram as diferenças e similaridades entre as agroindústrias da AF e da ANF para os oito produtos em análise.

\section{AGROINDÚSTRIAS FAMILIARES E NÃO FAMILIARES: DISTINÇÕES E HETEROGENEIDADES}

No último censo agropecuário houve a coleta de dados em cada estabelecimento do Brasil sobre o processamento e a transformação de produtos agrícolas, e, portanto, sobre as

\footnotetext{
${ }^{3}$ O estabelecimento é uma unidade de produção dedicada total ou parcialmente a atividades agropecuárias, florestais ou aquícolas, dirigido pelo produtor ou por um administrador. O estabelecimento é assim definido pelo IBGE sem considerar o seu tamanho, a sua localização, se em área urbana ou rural, ou a sua forma jurídica e se tem como objetivo a produção para subsistência e/ou para venda. Além destes estabelecimentos, no Censo Agropecuário foram coletados os dados das "fazendas, hortos, postos zootécnicos, estações experimentais, hotéis-fazenda, bem como as explorações agrícolas, florestais e/ou aquícolas de conventos, hospitais, asilos, orfanatos, escolas profissionais, patronatos, reformatórios, prisões ou locais para lazer, desde que tenham tido exploração agropecuária, florestal e/ou aquícola, ficando sujeitas ao levantamento apenas as atividades ligadas diretamente a estas explorações" (IBGE, 2007, p. 20). Neste artigo, foram pesquisados somente os estabelecimentos que têm agroindústrias rurais.

${ }^{4}$ Estes mesmos oito produtos, com adição dos Pães, Bolos e Biscoitos, foram selecionados com base nos mesmos critérios de escolha apontados neste trabalho, para escrever dois outros artigos apresentados no Congresso da SOBER (2011). Estes artigos são "Perfil produtivo da agroindústria rural nas regiões brasileiras: uma análise a partir dos dados do Censo Agropecuário de 2006" e "Os mercados e canais de comercialização para os produtos da agroindústria rural no Brasil: um comparativo macrorregional".
} 
agroindústrias rurais. Analisando esses dados, no que se refere à agroindústria da agricultura familiar (AF) e da agricultura não familiar (ANF) para a variável número de estabelecimentos, foi identificado que a grande maioria dos estabelecimentos que transformaram produtos agrícolas eram os familiares. Somados os estabelecimentos familiares, produtores dos oito produtos analisados neste artigo compõem um total de 405.647 unidades produtivas enquanto que os não familiares são 45.922 (Tabela 1). Assim, do total destes estabelecimentos $89 \%$ são familiares e $11 \%$ são não familiares.

Se considerados todos os estabelecimentos do Brasil, verifica-se que existem aproximadamente $84 \%$ da AF e $16 \%$ da ANF (IBGE, 2009). Valores parecidos aos da distribuição da agroindústria rural entre as unidades transformadoras da AF e da ANF citados no parágrafo anterior. Assim, constata-se que a disposição entre estabelecimentos da AF e da ANF que têm agroindústrias para estes produtos analisados, mantém-se muito próxima à forma como está composta a estrutura agrária brasileira.

Tabela 1. Brasil - Número de Estabelecimentos que agroindustrializam alimentos, na $A F$ e na ANF

\begin{tabular}{l|r|r|r} 
Produtos agroindustriais & Agricultura familiar & Agricultura não familiar & \multicolumn{1}{c}{ TOTAL } \\
\hline Fubá de milho & 6306 & 1132 & 7438 \\
Farinha de mandioca & 245582 & 19300 & 264882 \\
Goma e/ou tapioca & 36558 & 3693 & 40251 \\
Queijo e/ou requeijão & 66064 & 14761 & 80825 \\
Aguardente de cana & 9229 & 1895 & 11124 \\
Rapadura & 13066 & 1614 & 14680 \\
Doces e geleias & 12838 & 1809 & 14647 \\
Embutidos & 16004 & 1718 & 17722 \\
\hline TOTAL & $\mathbf{4 0 5 6 4 7}$ & $\mathbf{4 5 9 2 2}$ & $\mathbf{4 5 1 5 6 9}$ \\
\hline
\end{tabular}

Fonte: Elaborado pelos autores com base no Censo Agropecuário de 2006 (IBGE).

Considerando essas proporções, na Figura 1 verifica-se que, por produto, os estabelecimentos da AF que agroindustrializaram no ano de 2006 compõem um leque que oscila para números superiores a $82 \%$, indo deste patamar para o produto queijo e/ou requeijão até $93 \%$ para a farinha de mandioca. Acima de $90 \%$ também estão os produtos goma e/ou tapioca (91\%) e embutidos (90\%). Em números absolutos, destaca-se a quantidade de estabelecimentos da AF para os produtos farinha de mandioca (245.582), queijo e/ou requeijão (66.064) e goma e/ou tapioca (36.558). Nesse caso, os produtos que detêm os maiores números absolutos também são os que detêm maior proporção de unidades transformadoras na $A F$.

Segundo Prezzoto (2002), a agroindustrialização faz parte da lógica da agricultura familiar, do preparo dos alimentos e consequentemente de sua história e cultura. Isso pode ajudar a entender por que existem mais destes estabelecimentos com esta atividade no Brasil.

Na ANF chama atenção o número de estabelecimentos inferior 1900 para cinco dos oito produtos em análise. Isso considerando todo o Brasil. 


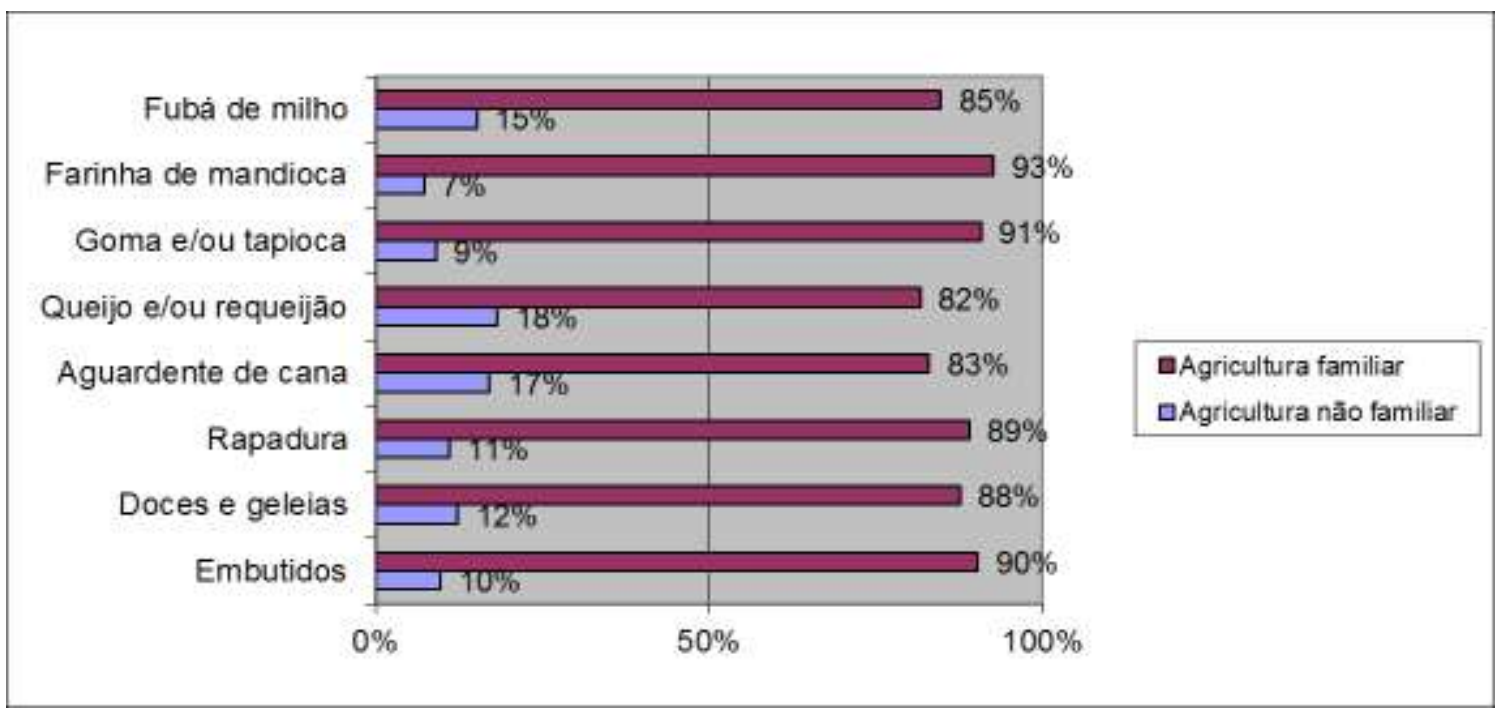

Figura 1. Brasil - Número de estabelecimentos que agroindustrializaram alimentos, na $A F$ e na ANF

Fonte: Elaborado pelos autores com base no Censo Agropecuário de 2006 (IBGE).

A quantidade de estabelecimentos produtores da farinha de mandioca, do queijo e/ou requeijão e da goma e/ou tapioca tanto na AF quanto na ANF são os mais elevados. Segundo Dias e Leonel (2006), a farinha de mandioca é difundida em todo o Brasil, mas especialmente no Norte e Nordeste e é consumida de diferentes formas (mingaus, farofas, pirão). É um alimento energético, rico em amido, fibras e em alguns minerais e por ser relativamente barato entra no cardápio principalmente das populações que têm menor renda. Segundo estes autores, a mandioca é beneficiada e transformada, porque é altamente perecível. Quando colhida ela precisa ser imediatamente consumida ou desidratada através de preparos que geram derivados como a farinha de mandioca e a goma e/ou tapioca.

O produto queijo e/ou requeijão é produzido em muitos estabelecimentos porque existem muitos produtores de leite que selecionam uma parcela desta matéria-prima para 0 consumo próprio in natura ou para transformação. Este é um produto que também é consumido com frequência pelos brasileiros. Talvez essas sejam as razões que explicam por que estes alimentos são amplamente difundidos entre os estabelecimentos no Brasil.

Na variável produção total há um comportamento distinto do observado na variável anterior. Ocorre diminuição na predominância da participação da AF. Observa-se que a supremacia da agricultura familiar verificada em todos os produtos analisados não se mantém. Entretanto, isso ocorre porque os números da produção da AF são inferiores aos da ANF em apenas um produto, a aguardente de cana. Para esse caso a ANF produziu o equivalente a $53 \%$. Dentre os estabelecimentos da AF tem destaque o percentual da produção global para os produtos farinha de mandioca e goma e/ou tapioca onde ocorre a produção de $93 \%$ e $94 \%$ da produção brasileira (1.243.867 t e 43.963 t). 


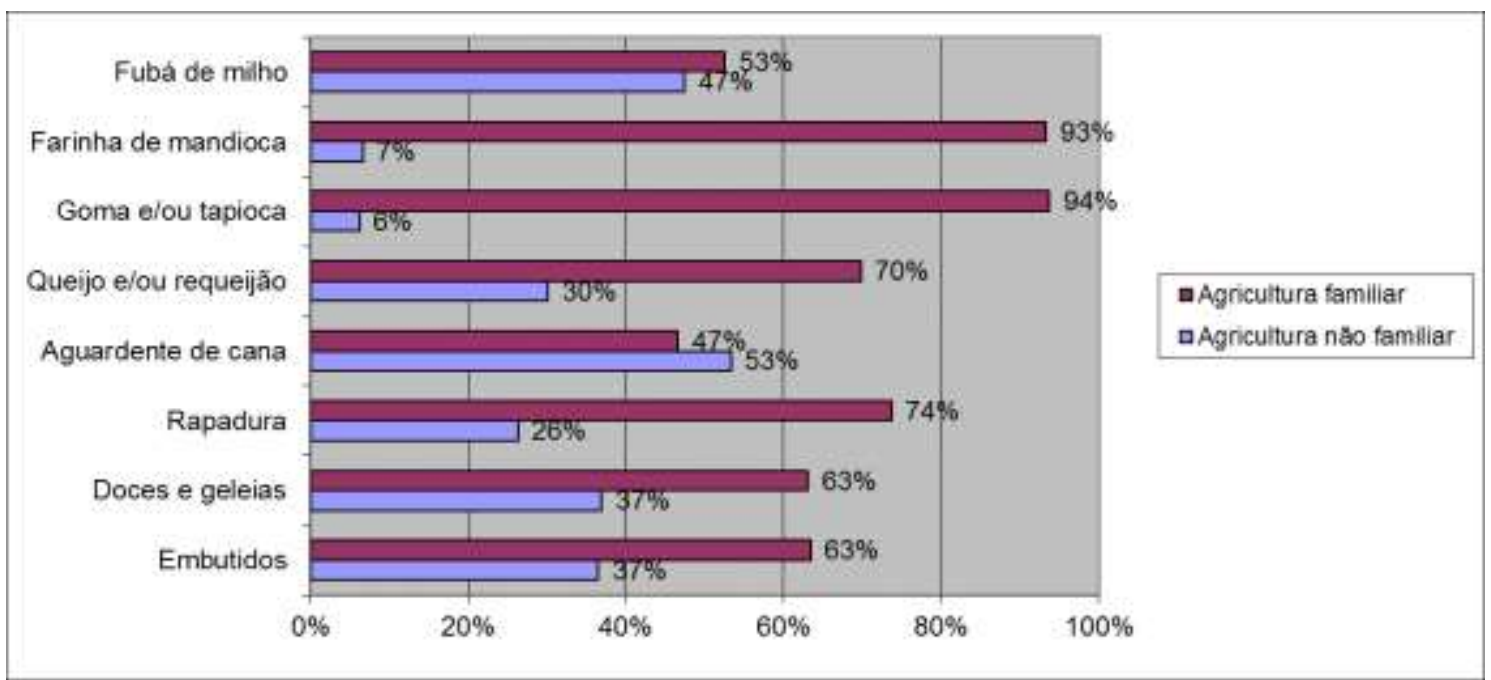

Figura 2. Brasil - Produção total da agroindústria rural, na AF e na ANF

Fonte: Elaborado pelos autores com base no Censo Agropecuário de 2006 (IBGE).

No caso desses dois últimos produtos, também se verificam valores altos para a $\mathrm{AF}$ na variável anterior. Como esses alimentos são tradicionais para a agricultura familiar das regiões Norte e Nordeste, servem de alimento para a família e excedentes podem ser comercializados. Por isso, aparecem valores expressivos para ambas as variáveis.

Para o produto aguardente de cana, a produção pela ANF em números percentuais é equivalente a $53 \%$, o que corresponde em números absolutos a algo que se aproxima de 60.400 mil litros por ano. Esse mesmo produto é um dos que detém um dos maiores números percentuais de estabelecimentos da ANF (17\%). Assim, na ANF este produto apresenta relação entre os totais das porcentagens de estabelecimentos e de quantidades produzidas, demonstrando que uma participação mais expressiva no número de estabelecimentos também determinou uma produção maior. Outro produto que se destaca por sua produção na ANF é o fubá de milho. São produzidos $47 \%$ ou 7.722 toneladas. Assim como para a aguardente de cana, para este produto também existem valores percentuais mais altos (15\%) de estabelecimentos da ANF que agroindustrializam produtos agrícolas no Brasil. Assim, na ANF é possível verificar que maiores proporções na produção total podem ser desencadeadas por números percentuais elevados de produtores.

Para a variável produção total, embora os números tenham demonstrado uma pequena superioridade da ANF no produto aguardente de cana, não há a comprovação de que a produção agroindustrial no espaço rural esteja perdendo o seu caráter de produção familiar, pois a diferença é de apenas algumas unidades decimais. Ela acontece nos estabelecimentos familiares de uma porcentagem que se aproxima a 50\% para apenas dois produtos. Para os demais, ela supera os $63 \%$, chegando a ser predominante na elaboração da farinha de mandioca e da goma e/ou tapioca. Essas proporções demonstram que a elaboração de produtos agroindustriais tem concentração em estabelecimentos familiares (Tabela 2). 
Tabela 2. Brasil - Produção total da agroindústria rural na AF e na ANF

\begin{tabular}{l|r|r|r} 
Produtos agroindustriais & Agricultura familiar & $\begin{array}{c}\text { Agricultura não } \\
\text { familiar }\end{array}$ & \multicolumn{1}{c}{ TOTAL } \\
\hline Fubá de milho $(t)$ & 8555 & 7722 & 16277 \\
Farinha de mandioca (t) & 1243867 & 89007 & 1332874 \\
Goma e/ou tapioca $(t)$ & 43963 & 2939 & 46902 \\
Queijo e/ou requeijão ( $t$ ) & 77849 & 33615 & 111464 \\
Aguardente de cana (Mil litros) & 52808 & 60400 & 113208 \\
Rapadura (t) & 24954 & 8918 & 33872 \\
Doces e geleias ( $t$ ) & 4010 & 2347 & 6357 \\
Embutidos $(t)$ & 1875 & 1079 & 2954 \\
\hline
\end{tabular}

Fonte: Elaborado pelos autores com base no Censo Agropecuário de 2006 (IBGE).

Outro aspecto da produção agroindustrial que os dados agregados do Censo Agropecuário permitem inferir, é que, com exceção da farinha de mandioca e da goma e/ou tapioca, a AF tem números elevados de estabelecimentos e tem menor representação na produção total revelando que os estabelecimentos familiares produtores de "agroindustrializados" se destacam por serem numerosos e por terem uma escala produtiva menor dos não familiares.

Conforme a escala produtiva, é possível inferir se os produtos são destinados para a venda ou se são retidos no interior na unidade, para consumo, estocagem ou troca com vizinhos. Quanto maior a escala produtiva, maior será a porcentagem vendida, pois em estabelecimentos em que é produzido em média mais de 30 mil litros de aguardente de cana por ano, provavelmente se destina grande parte da produção para o exterior da unidade produtiva. Desse modo, acredita-se que, em cada uma das unidades agroindustriais rurais do Brasil, tanto para aquelas que operam na informalidade como para as formais, haja produção para um ou dois destinos. Ou ocorre predominantemente a produção para suprir a demanda por alimentação da família e/ou os produtos são destinados para venda.

Observando a Tabela 3, verificam-se distintas escalas produtivas que variam conforme a agricultura, familiar ou não familiar, e conforme o produto da agroindústria. $\mathrm{Na}$ $\mathrm{AF}$ as agroindústrias têm uma escala produtiva média que oscila de 0,1 e 0,3 toneladas por ano e por estabelecimento para os produtos embutidos e doces e geleias. Outros quatro produtos têm uma escala produtiva um pouco mais elevada: são produzidos 1,2 tonelada dos produtos goma e/ou tapioca e queijo e/ou requeijão, 1,4 toneladas do fubá de milho e 1,9 da rapadura. Para dois outros produtos a escala produtiva média supera as cinco toneladas por estabelecimento. Esses são a farinha de mandioca com produção de 5,1 toneladas e a aguardente de cana com produção de 5,7 mil litros. 
Tabela 3. Brasil - Escalas produtivas médias das agroindústrias rurais familiares e não familiares

\begin{tabular}{l|c|c} 
Produtos agroindustriais & Agricultura familiar & Agricultura não familiar \\
\hline Fubá de milho $(t)$ & 1,4 & 6,8 \\
Farinha de mandioca (t) & 5,1 & 4,6 \\
Tapioca e/ou goma (t) & 1,2 & 0,8 \\
Queijo e/ou requeijão (t) & 1,2 & 2,3 \\
Aguardente de cana (Mil litros) & 5,7 & 31,9 \\
Rapadura (t) & 1,9 & 5,5 \\
Doces e geleias ( $t$ ) & 0,3 & 1,3 \\
Embutidos ( $t$ ) & 0,1 & 0,6 \\
\hline
\end{tabular}

Fonte: Elaborado pelos autores com base no Censo Agropecuário de 2006 (IBGE).

$\mathrm{Na}$ ANF as escalas têm uma amplitude maior, variando de 0,6 tonelada para os embutidos e 0,8 para a goma e/ou tapioca. Para os doces e geleias são 1,3 tonelada e para o queijo e/ou requeijão são 2,3. Valores relativos à escala que são superiores a estes são observados nos produtos farinha de mandioca $(4,6$ toneladas), rapadura $(5,5)$ e fubá de milho $(6,8)$. Nessa agricultura, tem destaque o produto aguardente de cana onde são produzidos em média 31,9 mil litros por ano por unidade produtiva.

Observando a escala produtiva destes oito produtos, verifica-se que em seis ela é superior na ANF e em dois na AF (farinha de mandioca e goma e/ou tapioca). Assim, de maneira geral, verifica-se que há uma relação entre o tamanho do estabelecimento e a capacidade de produção das agroindústrias, considerando que para a maioria dos produtos, nos estabelecimentos da ANF, a capacidade produtiva agroindustrial é maior do que a capacidade dos estabelecimentos da AF. Isso tem a ver com a lógica diferente dessas agriculturas, uma vez que a AF está mais focada na diversificação, enquanto que na ANF observa-se a tendência para desenvolver um único cultivo ou atividade econômica. Isso possibilita que as agroindústrias rurais da ANF operem em maior escala.

Seguindo na análise das variáveis, os dados relativos às Figuras 3 e 4, que tratam sobre a origem da matéria-prima, demonstram que para todos os produtos as agroindústrias não familiares compram mais matéria-prima. Isso corrobora um aspecto de que a AF tem a característica de produzir maior variedade de cultivos e criações e de produzir em menor escala do que a ANF. Com intuito de elaborar o seu próprio alimento, estas famílias produzem variados cultivos e criam animais para o abate, pois elas não têm como único objetivo a produção para o mercado, mas as atividades giram em torno de um conjunto de necessidades a serem atendidas, dentre elas está a de garantir a sua alimentação. Assim, do total de produtos agrícolas produzidos, uma determinada porção é destinada para o consumo da família. Desse modo, para a variável origem da matéria-prima, é natural que apareça uma quantidade mais expressiva da produção agroindustrial proveniente de meios próprios. 
Prezzoto (2002) cita que quando a produção agroindustrial consegue ser suprida com matérias-primas que provêm principalmente da propriedade ou das propriedades, que gerenciam a agroindústria, ocorre agregação de valor ao produto agropecuário. Se fosse necessário obter muita matéria-prima do exterior do estabelecimento, poderia ocorrer falência, pois seria necessário haver com frequência receitas no caixa da agroindústria, o que nem sempre está disponível. Assim, segundo a lógica familiar destes estabelecimentos, só há razão para a agroindustrialização se houver agregação de valor à produção própria. Se fossem compradas matérias-primas haveria a incidência de custos de produção e transação, podendo inviabilizar economicamente a agroindústria.

Conforme a Figura 3, na AF a produção agroindustrial com matéria-prima de origem própria é igual ou superior a $75 \%$. Alcança valores equivalentes a $91 \%$ para a rapadura, 90\% para a farinha de mandioca, $89 \%$ para o queijo e/ou requeijão e $88 \%$ para a goma e tapioca. Para os outros quatro produtos observam-se valores percentuais menores, mas que não deixam de ser expressivos.

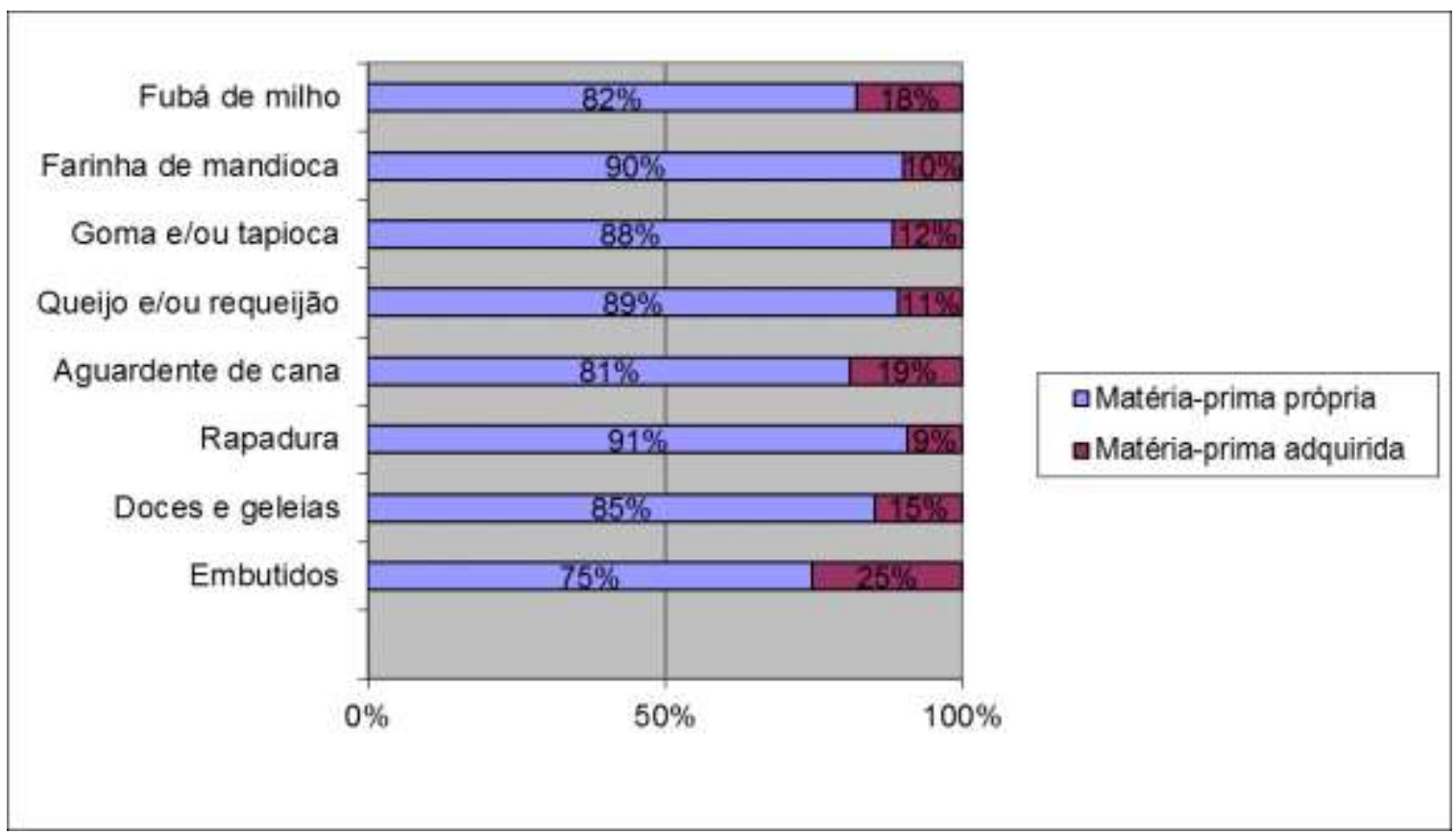

Figura 3. Brasil - Origem da matéria-prima da agroindústria rural, na AF

Fonte: Elaborado pelos autores com base no Censo Agropecuário de 2006 (IBGE).

$\mathrm{Na}$ Figura 4, para a ANF os produtos com menor participação percentual de matéria prima própria foram: fubá de milho, embutidos e doces e geleias. São 58\% para o fubá de milho, $42 \%$ para os embutidos e $32 \%$ para os doces e geleias. Nesses três últimos produtos, estaria a maior diferença entre AF e ANF na variável origem da matéria prima. Entretanto, a ANF também apresenta valores da matéria-prima própria consideráveis para os produtos rapadura, queijo e/ou requeijão e farinha de mandioca. 


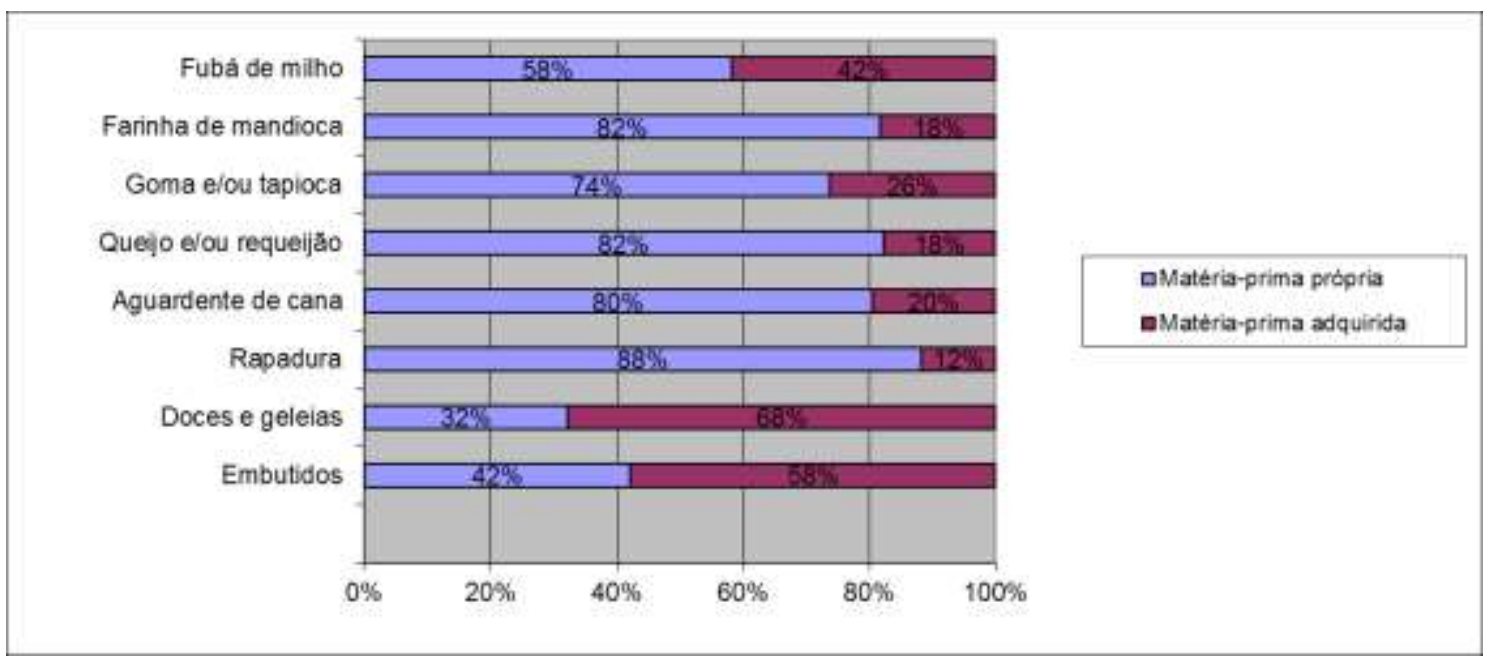

Figura 4. Brasil - Origem da matéria-prima da agroindústria rural, na ANF

Fonte: Elaborado pelos autores com base no Censo Agropecuário de 2006 (IBGE).

Ademais, observando essa discussão sobre a origem da matéria-prima, destaca-se a similaridade entre AF e ANF para o produto rapadura e aguardente de cana uma vez que a quantidade de matéria-prima adquirida e a proveniente do próprio estabelecimento se distanciam em 3\% e 1\%, respectivamente.

Seguindo na análise das variáveis, as Figuras 5 e 6 demonstram, em valores percentuais, a quantidade da produção que foi comercializada (quantidade vendida dividida pela quantidade total produzida) na $A F$ e na $A N F$, respectivamente. Cabe ressaltar que, na $A F$, esses dados revelam que a grande maioria dos produtos tem como destinação a venda, com exceção dos produtos fubá de milho e embutidos que têm mais da metade da produção direcionada a outros destinos, sejam eles consumo nos estabelecimentos, troca com vizinhos e estocagem. Para os outros seis produtos, a proporção de alimentos que foi vendida alcança valores superiores a $65 \%$.

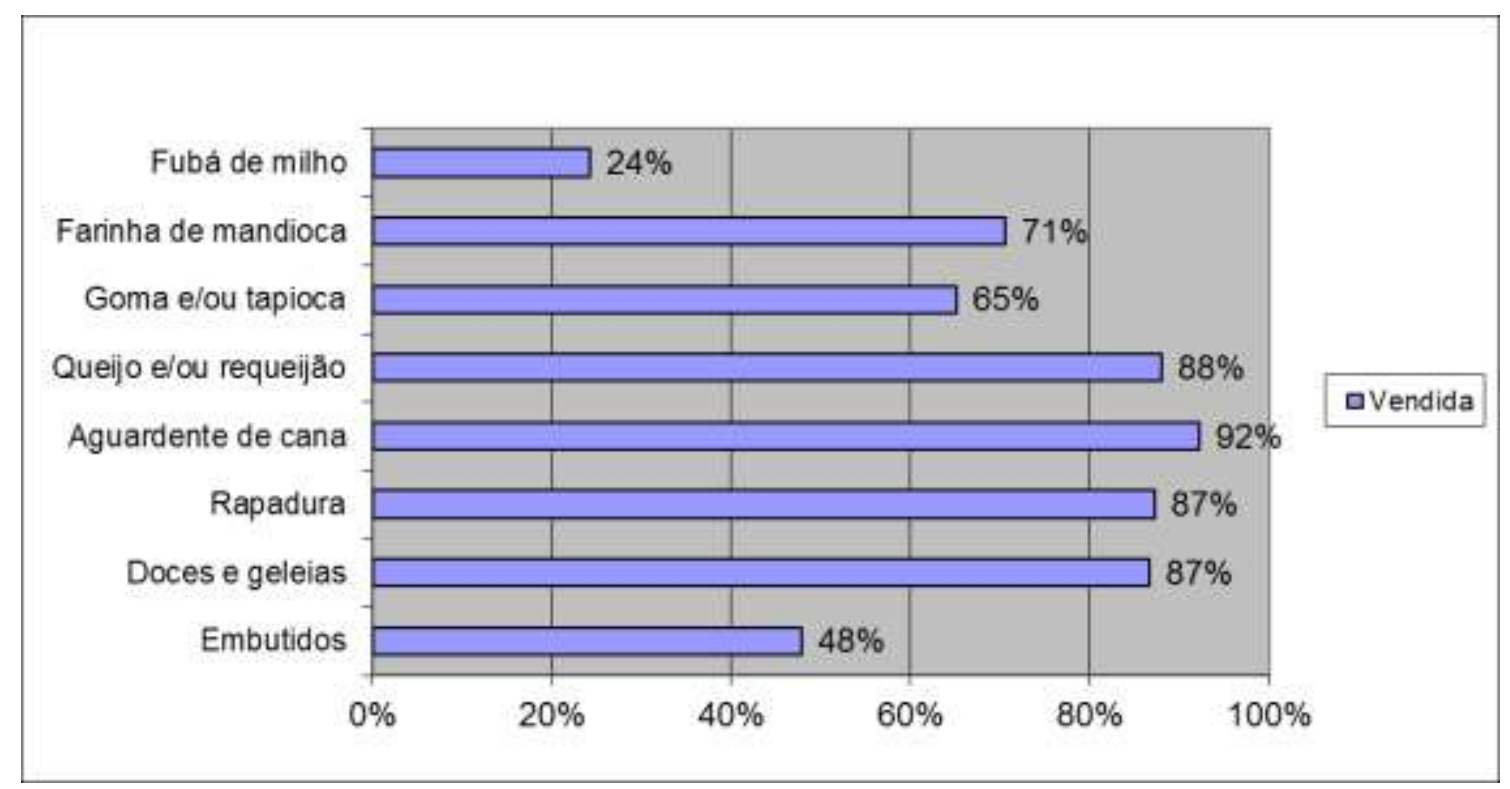

Figura 5. Brasil - proporção vendida da produção total da agroindústria rural, na AF

Fonte: Elaborado pelos autores com base no Censo Agropecuário de 2006 (IBGE). 
Conforme a Figura 6, na ANF o produto fubá de milho também se destaca por ser 0 produto com menor comercialização (58\%). Desponta a porcentagem da produção comercializada da rapadura (91\%), do queijo e/ou requeijão (92\%), da aguardente de cana $(94 \%)$ e dos doces e geleias $(97 \%)$. Vale destacar que os doces e geleias são quase completamente comercializados.

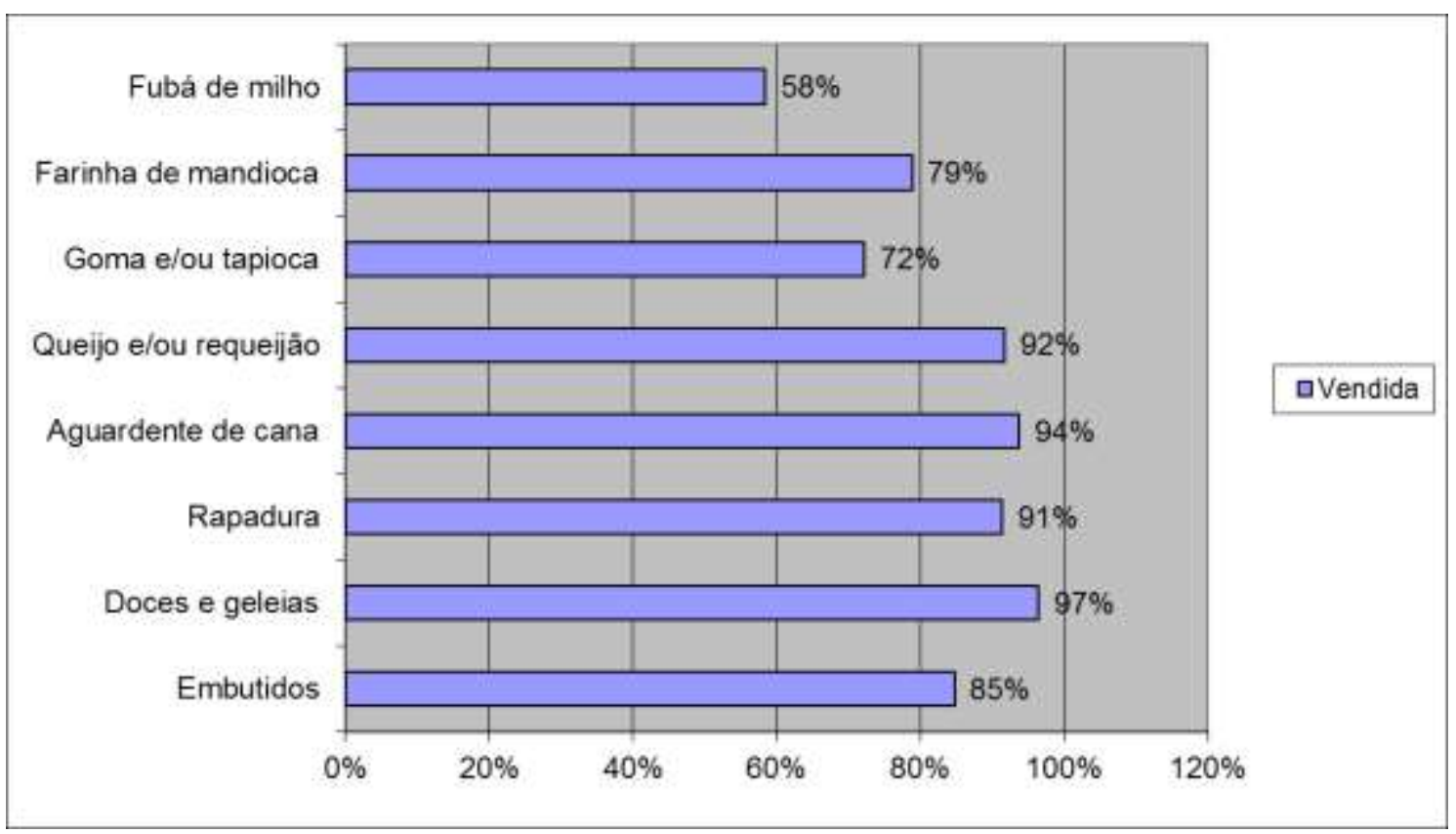

Figura 6. Brasil - Proporção de venda da produção total da agroindústria rural, na ANF

Fonte: Elaborado pelos autores com base no Censo Agropecuário de 2006 (IBGE).

Os produtos queijo e/ou requeijão, aguardente de cana, rapadura e doces e geleias têm características parecidas na $A F$ e na $A N F$, destinando-se em maior proporção para comercialização do que o restante dos produtos analisados. São comercializados na agricultura familiar em números superiores a $87 \%$ e na não familiar a $91 \%$.

Comparando, de maneira geral, a porcentagem de venda dos produtos, percebe-se que a ANF vende mais do que a AF. Essa característica auxilia na comprovação de que os alimentos da agroindústria rural produzidos em estabelecimentos familiares são mais destinados ao consumo no interior da unidade produtiva, e, portanto, são para o autoconsumo da família, como estudos já evidenciaram (GRISA, 2007). Outro fator que está relacionado com a comercialização é a escala produtiva, como visto, para a maioria dos produtos analisados a ANF tem potencial de produzir em escala maior do que a AF e isso contribui para que maiores proporções da produção sejam vendidas.

$A$ diferença entre $A F$ e $A N F$, no que tange às diferentes formas de escoamento da produção comercializada, pode ser observada segundo as quantidades vendidas ou 
entregues a terceiros. Nas próximas figuras são analisados os principais canais de comercialização (venda a intermediário, direta ao consumidor e outra ${ }^{5}$ ).

Conforme a Figura 7, na AF os produtos que superam em mais de $60 \%$ a venda direta a intermediários são: rapadura (82\%), aguardente de cana $(83 \%)$, queijo e/ou requeijão $(70 \%)$, goma e/ou tapioca $(72 \%)$ e farinha de mandioca $(83 \%)$. Os embutidos e os doces e geleias têm como principal destino a venda direta ao consumidor (68\% e $74 \%$ ).

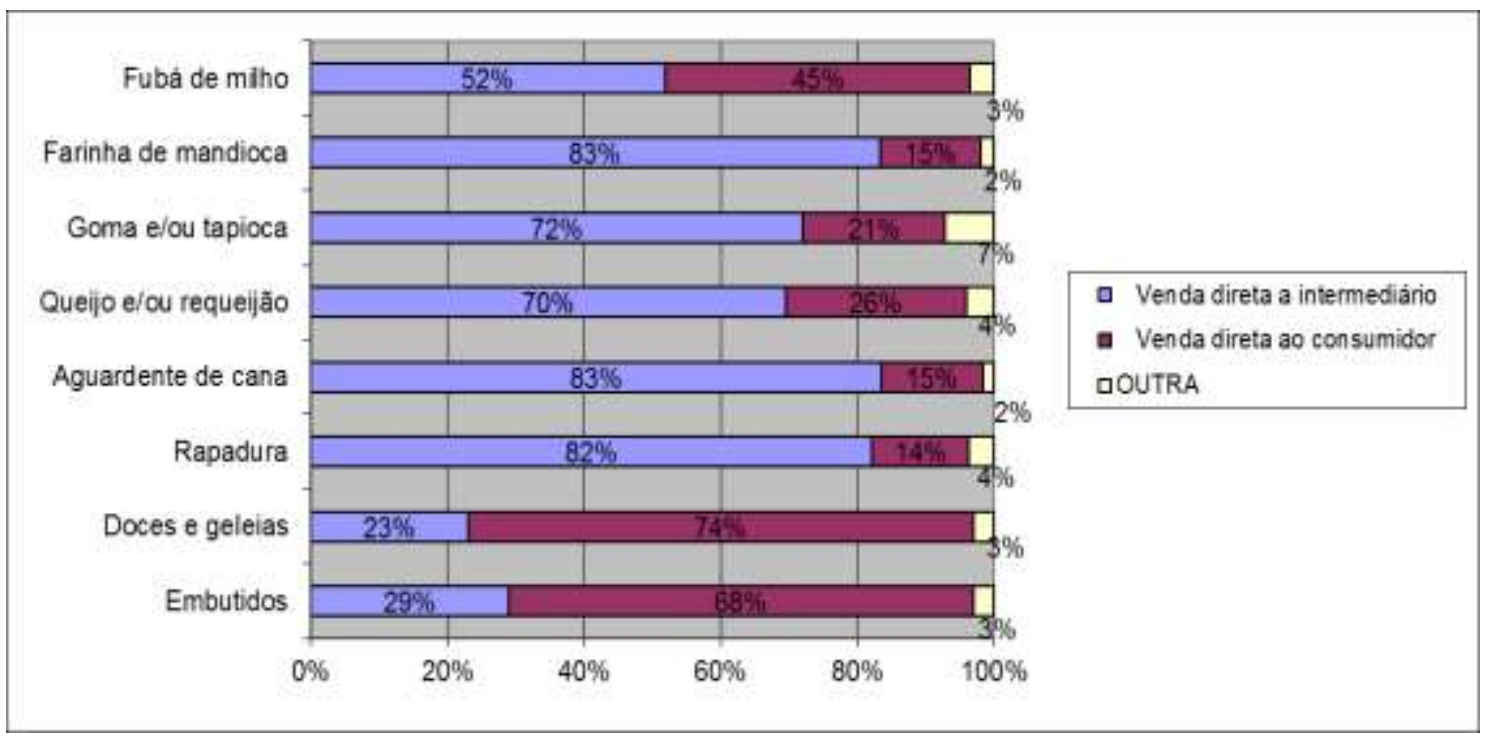

Figura 7. Brasil - Destinos da produção total vendida, na AF

Fonte: Elaborado pelos autores com base no Censo Agropecuário de 2006 (IBGE).

Observando os principais destinos dos produtos da agroindústria na ANF, verifica-se que, com exceção da aguardente de cana, há comercialização em mais de $73 \%$ para os intermediários. Menos de $25 \%$ da produção total é vendida ao consumidor final. Para a aguardente de cana, o principal canal de escoamento acontece através da categoria Outras e tem como principal destino a venda para cooperativas, indústria e empresa integradora.

\footnotetext{
${ }^{5}$ A categoria "OUTRA" inclui os seguintes destinos somados: venda ou entregue a cooperativas, venda para a indústria, entregue à empresa integradora, venda entregue ou doada ao governo federal ou estadual e exportada.
} 


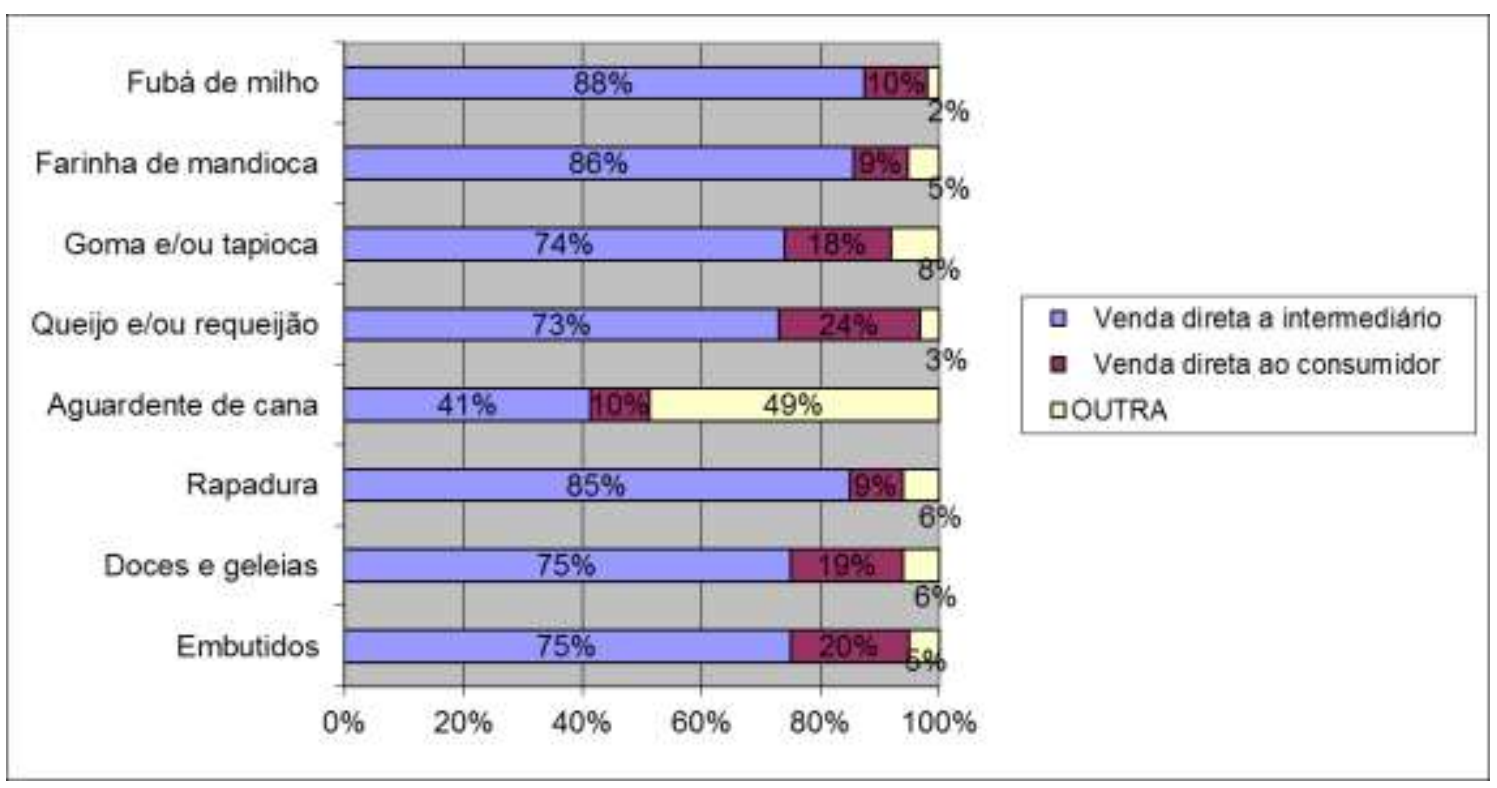

Figura 8. Brasil - Destinos da produção vendida, na ANF

Fonte: Elaborado pelos autores com base no Censo Agropecuário de 2006 (IBGE).

Com exceção da aguardente de cana, a ANF entrega mais de todos os produtos para os intermediários do que o faz a AF. O anterior pode ser explicado pelo fato de que a produção em pequena escala precisa de agregação de valor até chegar ao consumidor final para poder permitir a mínima estabilidade econômica e a permanência na atividade produtiva. Inserindo o intermediário na comercialização, os lucros diminuem, pois é mais um agente antes de chegar ao consumidor final. Vendendo diretamente ao consumidor há possibilidade de agregar o valor que seria incorporado pelo intermediário.

Além disso, para vender a intermediários, por vezes é exigido uma determinada escala de produção, regularidade na oferta e padronização da produção. Com escala de produção maior, as agroindústrias da ANF teriam condições de atender melhor a estas condições (PREZZOTO, 2002). Para atender às exigências de regularidade na oferta, a ANF pode estar obtendo matéria-prima, em momentos em que sua matéria-prima própria foi toda transformada. Já a agroindústria da $A F$, que geralmente transforma principalmente os alimentos que ela mesma produz, encontra mais dificuldade para manter uma oferta regular e padronizada, pois, de um ano para o outro, as safras variam em quantidade e qualidade 0 que causa alterações no alimento agroindustrializado.

\section{Considerações Finais}

Os dados analisados permitiram de maneira genérica vislumbrar algumas das diferenças entre as agroindústrias da AF e da ANF. Considerando que os dados estavam agregados para o Brasil como um todo, não foi possível fazer uma análise para as grandes regiões do país ou em nível local. Todavia, permitiram constatar e quantificar o global da AF e ANF.

Conforme os resultados apontados no artigo, destaca-se que a atividade agroindustrial no Brasil caracteriza-se pela maior proporção de estabelecimentos da AF. Essa proporção se aproxima da relativa à totalidade de estabelecimentos da AF no Brasil, pois são 
em números percentuais semelhantes. No caso da produção total, passam a existir com mais destaque os números da ANF, com superioridade dessa em $6 \%$ para o produto aguardente de cana. Entretanto, para o restante dos produtos as principais quantidades produzidas são provenientes da AF. No geral, esses dados revelam que a atividade da agroindústria rural acontece em mais propriedades familiares que são numerosas e pequenas e que somadas as parcelas que cada uma produz para cada produto obtêm-se uma quantidade superior à produzida na ANF.

O aparecimento da ANF em maiores valores na produção total, considerando que aparece menos na variável relativa aos estabelecimentos, deve-se às escalas das agroindústrias que só não ultrapassam as da AF em dois produtos: a farinha de mandioca e a goma e/ou tapioca. Esses são alimentos consumidos em grande quantidade pelas famílias de baixa renda e dentre essas podem estar os agricultores que têm propriedades menores. Afora esses produtos, a maior escala de produção pode estar relacionada à lógica diferente que gere os estabelecimentos. A AF, tendo propriedades mais diversificadas, pode ter a agroindústria como atividade complementar. Já a ANF, por ser em sua maioria mais especializada, pode ter a agroindústria como atividade principal e como única fonte de renda.

A variável relacionada com a matéria-prima revela informações importantes sobre as agroindústrias. $A$ ANF, obtendo maiores proporções de matéria-prima, pode estar buscando manter regularidade de oferta ou pretendendo não deixar ociosas as agroindústrias que têm alta capacidade de processamento. Já a AF que obtém menor proporção de matéria-prima pode estar usando a sua lógica de não adquirir para poder agregar mais valor. Tendo a agroindústria como atividade complementar, a AF não se interessa em produzir mais do que propicia a matéria-prima produzida em seu estabelecimento, pois tem outras fontes de renda. Entretanto, nas propriedades da $A F$, que têm as agroindústrias como principal atividade, podem ser adquiridas matérias-primas. Infelizmente não é possível visualizar nos dados agregados se realmente é isso que ocorre: agroindústrias com escalas maiores, dentre as da AF, compram em maiores proporções as matérias-primas que as agroindústrias caseiras.

A proporção da produção total vendida entre os estabelecimentos da AF e da ANF mostra relação com a escala produtiva, pois os estabelecimentos que agroindustrializam para além da sua capacidade de consumo precisam escoar a sua produção (a menos que estoquem ou troquem com vizinhos). Por isso, a ANF vende mais porque cada agroindústria tem em média capacidade de produzir maiores quantidades. É assim para seis dos oito produtos analisados. Entretanto, a AF também vende grandes proporções da sua produção, o que pode indicar que boa parte de sua produção total é proveniente de agroindústrias que são a principal atividade dos estabelecimentos.

Dentre a produção vendida, revelam-se distintos canais de comercialização. $\mathrm{Na} \mathrm{AF}$, aparece principalmente a venda a intermediários e a consumidores. Algo similar ocorre na ANF, com a diferença de que os intermediários adquirem em maiores proporções do que na AF. Na ANF há uma exceção, pois a aguardente é vendida em grandes proporções à indústria e à cooperativa, o que não aparece tão expressivamente para os outros produtos $e$ para a AF.

Para finalizar, pode-se dizer o seguinte: considerando que a agroindústria é uma atividade típica da $A F$, essa agrega mais valor ao produto, vendendo em maior proporção diretamente ao consumidor final e adquirindo menos matéria-prima. A ANF tem escala 
produtiva maior, proporções maiores destinadas ao mercado e maior quantidade vendida aos intermediários já que, com escalas maiores, tem condições de suprir a demanda por regularidade na oferta. Essas são as principais distinções e similaridades que foram identificadas entre as agroindústrias da AF e da ANF. São agriculturas que, no geral, têm diferentes lógicas que, de maneira sutil, mas representativa, alteram a maneira como as agroindústrias são gerenciadas.

\section{REFERÊNCIAS}

BASTIAN, L.; SANTOS, F.; BLUME, R.; GAZOLLA, M.; NIEDERLE, P.A. Perfil produtivo da agroindústria rural nas regiões brasileiras: uma análise a partir dos dados do Censo Agropecuário de 2006. In: CONGRESSO DA SOCIEDADE BRASILEIRA DE ECONOMIA, ADMINISTRAÇÃO E SOCIOLOGIA RURAL, 49. Belo Horizonte. Anais... Brasília: Sober, 2011.

DIAS, L. T.; LEONEL, M. Caracterização físico-química de farinhas de mandioca de diferentes localidades do Brasil. Ciência e Agrotecnologia, Lavras, v. 30, n. 4, p. 692-700, 2006. Disponível em: <http://www.scielo.br/pdf/cagro/v30n4/v30n4a15.pdf>. Acesso em 8 nov. 2011.

FROEHLICH, J. M. Rural e natureza: a construção social do rural contemporâneo na região central do Rio Grande do Sul. 2002. Tese (Doutorado em Desenvolvimento, Agricultura e Sociedade) - Instituto de Ciências Humanas e Sociais, Universidade Federal Rural do Rio de Janeiro, Rio de Janeiro, 2002.

GRISA, C. Para além da alimentação: papéis e significados da produção para autoconsumo na agricultura familiar. Revista Extensão Rural, Santa Maria, p. 5-36, jan. dez. 2007. Disponível em: <http://w3.ufsm.br/extensaorural/art1ed14.pdf>. Acesso em: 8 nov. 2011.

GUIMARÃES, G. M.; SILVEIRA, P. R. Por trás da falsa heterogeneidade do termo agroindústria familiar rural: indefinição conceitual e incoerências das políticas públicas. 2010. Disponível em: <http://www.cnpat.embrapa.br/sbsp/anais/Trab_Format_PDF/99.pdf>. Acesso em: 22 set. 2011.

INSTITUTO BRASILEIRO DE GEOGRAFIA E ESTATÍSTICA. Censo Agropecuário 2006. 2009. Disponível em: <http://www.sidra.ibge.gov.br/bda/pesquisas/ca/default.asp?o $=2 \& \mathrm{i}=\mathrm{P}>$. Acesso em: 24 jan. 2010.

INSTITUTO BRASILEIRO DE GEOGRAFIA E ESTATÍsTICA. Censo Agropecuário 2006: agricultura familiar. Rio de Janeiro, 2009. 1 CD-ROM.

INSTITUTO BRASILEIRO DE GEOGRAFIA E ESTATÍSTICA. Manual do recenseador. censo agropecuário 2006. Rio de Janeiro: [s.n.]: 2007. 
MIOR, L. C. Agricultura familiar, agroindústria e desenvolvimento territorial. 2007.

Disponível em: <http://www.cidts.ufsc.br/articles/Artrigo_Coloquio_\%20-_Mior.pdf>. Acesso em: 2 set. 2011.

MIOR, L. C. Trajetórias das agroindústrias familiares rurais no estado de Santa Catarina (Brasil). In: CONGRESSO INTERNACIONAL DE LA RED SIAL, 4., 2008, Mar Del Plata, Argentina. [mensagem pessoal]. Mensagem recebida por <lillianbstn@hotmail.com> em 01 set. 2011.

NIEDERLE, P.A.; GAZOLLA, M.; WAQUIL, P. D.; SANTOS, F.; BASTIAN, L. Os mercados e canais de comercialização para os produtos da agroindústria rural no Brasil: um comparativo macrorregional. In: CONGRESSO DA SOCIEDADE BRASILEIRA DE ECONOMIA, ADMINISTRAÇÃO E SOCIOLOGIA RURAL, 49. Belo Horizonte. Anais... Brasília: SOBER, 2011.

PREZOTTO, L. L. Qualidade ampla: referência para a pequena agroindústria rural inserida numa proposta de desenvolvimento regional descentralizado. 2008. Disponível em: $<$ www.mda.gov.br/dotlrn/clubs/redestematicasdeater/agroindstria/contents/photoflow view/content-view?object_id=921608 > . Acesso em: 12 set. 2011.

PREZOTTO, L. L. Uma concepção de agroindústria rural de pequeno porte. Revista de Ciências Humanas, Florianópolis, n. 31, p. 133-154, abr. 2002. Disponível em: <http://www.cfh.ufsc.br/ revista/rch31.pdf>. Acesso em: 10 set. 2011.

RAUPP, A. K. A orientação das políticas públicas de apoio às agroindústria da agricultura familiar. experiências do RS em destaque. In: CONGRESSO DA SOBER, 47., 2009, Porto Alegre. Disponível em: <http://www.sober.org.br/palestra/13/987.pdf>. Acesso em: 15 set. 2011.

WENZ JUNIOR, V. J. As políticas públicas de agroindustrialização na agricultura familiar. análise e avaliação da experiência brasileira. 2009. Dissertação (Mestrado em Ciências Sociais em Desenvolvimento, Agricultura e Sociedade) - Instituto de Ciências Humanas e Sociais, Universidade Federal Rural do Rio de Janeiro. Rio de Janeiro, 2009. Disponível em: $<$ http://www.ufrrj.br/cpda/static/teses/dissertacao_valdemar_wesz_junior.pdf $>$. Acesso em 13 out. 2011.

WILKINSON, J.; MIOR, L. C. Setor informal, produção familiar e pequena agroindústria: interfaces. Estudos Sociedade e Agricultura, v. 13, p. 29-45, out. 1999. Disponível em: <http://bibliotecavirtual.clacso.org.ar/ar/libros/brasil/cpda/estudos/treze/wilkin13.htm>. Acesso em: 25 set. 2011. 


\section{Sobre os autores \\ Lillian Bastian}

Mestre em Desenvolvimento Rural e Doutoranda em Desenvolvimento Rural pela Universidade Federal do Rio Grande do Sul (PGDR/UFRGS).

Endereço: Rua Manoel Batista Gomes, 225. CEP 95.960-000 - Sentinela do Sul - RS - Brasil.

Email: lillianbastian12@gmail.com

\section{Paulo Dabdab Waquil}

Doutor em Economia Agrícola. Professor associado da Universidade Federal do Rio Grande do

Sul/Departamento de Economia e Relações Internacionais (DERI).

Endereço: Rua Eça de Queiroz, 682/301. CEP 90.670-020 - Porto Alegre - RS - Brasil.

Email:waquil@ufrgs.br

\section{Mônica Concha-Amin}

Doutora em Economia Aplicada pela UFRGS. Docente na Fundação Universidade Federal de Ciências da Saúde de Porto Alegre - Departamento de Educação e Informação em Saúde (DEIS).

Endereço para correspondência: Rua São Luis, 662/705. CEP 90620-170- Porto Alegre - RS - Brasil.. Email: monicac@ufcspa.edu.br

\section{Márcio Gazolla}

Doutorado em Desenvolvimento Rural pela UFRGS. Professor da Universidade Federal de Santa Maria (CAFW) - Campus de Frederico Westphalen/ RS.

Endereço: Campus da UFSM. Linha 7 de Setembro, s/n. Caixa Postal: 54. CEP 98.400-000. Frederico Westphalen - RS - Brasil.

Email: marciogazolla1@gmail.com 